\title{
Is Systematic Sextant Biopsy Suitable for the Detection of Clinically Significant Prostate Cancer?
}

\author{
A. Manseck $^{a} \quad$ M. Froehner ${ }^{a} \quad$ S. Oehlschlaeger ${ }^{a} \quad$ O. Hakenberg ${ }^{a}$ \\ K. Friedrich ${ }^{b}$ F. Theissig ${ }^{b}$ M.P. Wirth ${ }^{a}$ \\ aDepartment of Urology and ${ }^{\mathrm{b}}$ Institute of Pathology, Technical University, Dresden, Germany
}

\section{Key Words}

Systematic sextant biopsy · Prostate cancer · Tumor stage $\cdot$ Radical prostatectomy tected by the conventional sextant biopsy. A negative sextant biopsy does not rule out significant prostate cancer.

Copyright $@ 2000$ S. Karger AG, Basel

\begin{abstract}
Background: The optimal extent of the prostate biopsy remains controversial. There is a need to avoid detection of insignificant cancer but not to miss significant and curable tumors. In alternative treatments of prostate cancer, repeated sextant biopsies are used to estimate the response. The aim of this study was to investigate the reliability of a repeated systematic sextant biopsy as the standard biopsy technique in patients with significant tumors which are being considered for curative treatment. Methods: Systematic sextant biopsy was performed in vitro in 92 radical prostatectomy specimens. Of these patients, $81(88.0 \%)$ had palpable lesions. $\boldsymbol{R e}$ sults: Of the 92 investigated patients, 70 (76.1\%) had potentially curable pT2-3pN0 prostate cancers. In these patients, the cancer was detected only in $72.9 \%$ of cases by a repeated in vitro biopsy. In the pT2 tumors, there was a detection rate of only $66.7 \%$. Conclusions: This study underlines the fact that a considerable number of significant and potentially curable tumors remain unde-
\end{abstract}

\begin{tabular}{ll}
\hline KARGER & ( ) 2000 S. Karger AG, Basel \\
$0042-1138 / 00 / 0652-0080 \$ 17.50 / 0$ \\
Fax +4161306 12 34 & \\
$\begin{array}{l}\text { E-Mail karger@karger.ch } \\
\text { www.karger.com }\end{array}$ & $\begin{array}{l}\text { Accessible online at: } \\
\text { www.karger.com/journals/uin }\end{array}$
\end{tabular}

\section{Introduction}

In the pre-prostate-specific antigen (PSA) era, prostate cancer $(\mathrm{CaP})$ was generally detected when a suspicious finding in the digital rectal examination (DRE) led to a finger-guided biopsy of the prostate. The widespread use of PSA screening increased the incidence of CaP dramatically [1]. As a consequence, the rising trend in $\mathrm{CaP}$ mortality was slightly reversed [1]. Hodge et al. [2] were the first to suggest ultrasound-guided transrectal sextant biopsy for the diagnosis of the palpably abnormal prostate. Although this technique is considered by many to be the standard procedure $[3,4]$, there is an ongoing controversy on the optimal extent of the prostate biopsy. The objective of this study was therefore to investigate the reliability of a repeated systematic sextant biopsy as the standard biopsy technique in patients with significant tumors which are considered curable. 
Table 1. Tumor classification and number of positive biopsies

\begin{tabular}{lrlll}
\hline Stage & $\mathrm{n}$ & $\begin{array}{l}\text { At least one } \\
\text { positive biopsy }\end{array}$ & $\begin{array}{l}\text { No positive } \\
\text { biopsy core }\end{array}$ & $\begin{array}{l}\text { Average number } \\
\text { of positive biopsy } \\
\text { cores (range) }\end{array}$ \\
\hline pT2pN0M0 & 36 & $24(66.7 \%)$ & 12 & $1.3(0-6)$ \\
pT3pN0M0 & 34 & $27(79.4 \%)$ & 7 & $2.2(0-6)$ \\
pT4apN0M0 & 13 & $13(100 \%)$ & 0 & $3.7(1-6)$ \\
pT2-4pN1M0 & 9 & $8(88.9 \%)$ & 1 & $2.9(0-5)$ \\
\hline Total & 92 & 72 & 20 & $2.2(0-6)$ \\
\hline
\end{tabular}

\section{Materials and Methods}

Ninety-two patients with pathohistologically-proven $\mathrm{CaP}$ were admitted to the study. Prostate specimens obtained by radical prostatectomy were used to simulate in vitro a systematic random biopsy. The patients were aged between 48 and 76 years (mean 58.2). The PSA value ranged between 0.2 and $149 \mathrm{ng} / \mathrm{ml}$ (mean 15.7). All patients were judged to have a clinically localized cancer. Eleven patients had only PSA-diagnosed tumors (cT1c), 81 patients had clinically palpable and localized $\mathrm{CaP}$ without distant metastases and prior therapy. Patients with neoadjuvant hormonal treatment were excluded from this study. Patients underwent clinical staging evaluation consisting of physical examination with DRE, chest X-ray, bone scan, transrectal and abdominal ultrasound as well as measurement of serum PSA levels prior to DRE and radical prostatectomy. After radical prostatectomy a randomized systematic biopsy from the radical prostatectomy specimen was performed using a Biopty-Gun ${ }^{\circledR}$ with an 18-gauge needle in the theater. In all prostates, 6 biopsy cores were obtained. The 6 biopsy sites were located at the apex, middle and the basis of the prostate bilaterally, as described by Hodge et al. [2] (fig. 1). The biopsy cores were then fixed in formalin. The following histological examination of the radical prostatectomy specimen was done according to a discretely modified McNeal technique [5]. The staging procedure was carried out using the TNM classification of 1997. The mean number of positive biopsies obtained in patients with a certain tumor stage was compared using the Mann-Whitney test.

\section{Results}

The results of the histological examination of the specimens obtained after radical prostatectomy and the results of the in vitro biopsies are shown in table 1 and 2 . The most common tumor classification was $\mathrm{pT} 2 \mathrm{pN} 0(\mathrm{n}=36$, $39.1 \%)$, followed by $\mathrm{pT} 3 \mathrm{pNO}(\mathrm{n}=34,37.0 \%)$ and pT4apN0 ( $\mathrm{n}=13,14.1 \%)$. Lymph node involvement was found in 9 patients $(9.8 \%)$. Of the 92 patients enrolled in this study, no cancer was found in all 6 biopsy cores in 20 cases $(21.7 \%), 72(78.3 \%)$ had at least 1 positive postoperative biopsy core. Among the 36 patients with pT2pN0
Table 2. Comparison of the number of positive biopsies according to the TNM classification of the tumors

\begin{tabular}{ll}
\hline Compared tumor classifications & p value (Mann-Whitney test) \\
\hline pT2pN0M0 vs. pT3pN0M0 & 0.015 \\
pT2pN0M0 vs. pT4apN0M0 & 0.000 \\
pT2pN0M0 vs. pT2-4pN1M0 & 0.018 \\
pT3pN0M0 vs. pT4apN0M0 & 0.018 \\
pT3pN0M0 vs. pT2-4pN1M0 & 0.29 \\
\hline
\end{tabular}

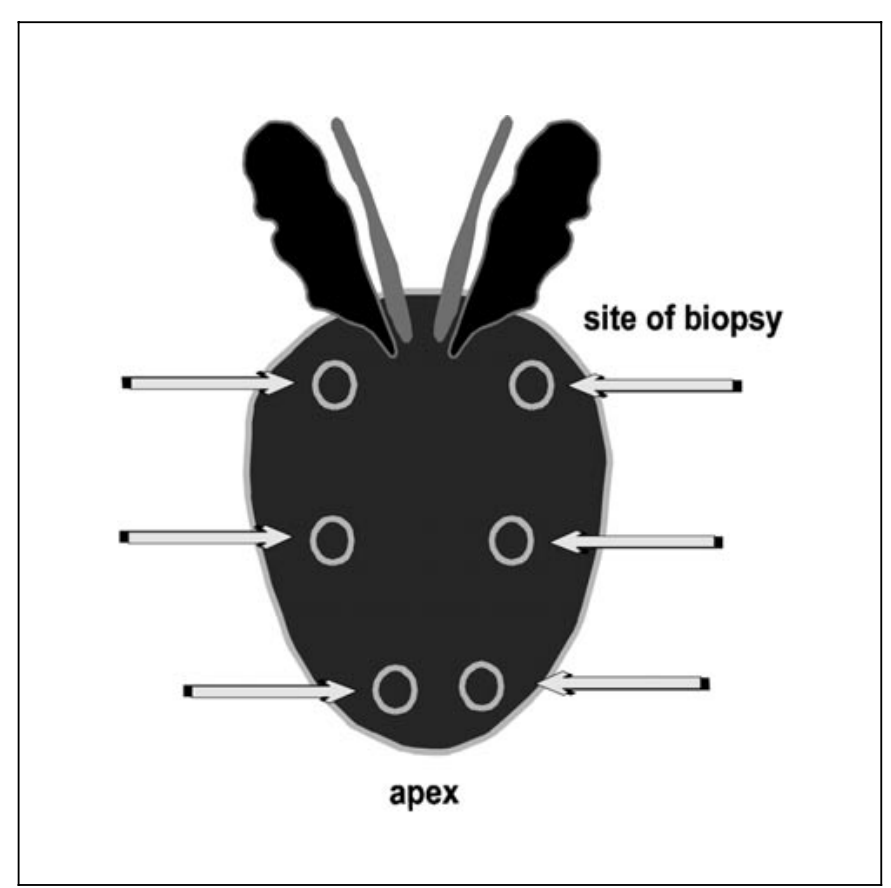

Fig. 1. Location of the in vitro biopsy sites after radical prostatectomy. 
tumor, cancer was detected by in vitro random biopsy in 24 cases $(66.7 \%)$, among the 34 patients with stage pT3pN0, cancer was detected in 27 cases $(79.4 \%)$. All but 1 of the 22 patients with stage pT4apN0 or pT2-4pN1 had at least 1 positive biopsy core (table 1 ). Considering the potentially curable tumor stages pT2-3pN0 together $(\mathrm{n}=$ $70)$, repeated sextant biopsies were negative in 19 cases $(27.1 \%)$. The number of positive biopsy cores of the repeated biopsy is given in table 1 .

\section{Discussion}

The results of this study demonstrate that random sextant biopsy of the prostate obtained postoperatively from radical prostatectomy specimens leaves a considerable portion (21.7\%) of clinically significant CaPs undetected. Only repeat biopsies in the incurable tumor stages pT4 or pN1 were nearly uniformally positive. In patients with a pT2 tumor, every third tumor remains undetected by repeat biopsy. In a study of 193 patients with T1c tumors by Epstein et al. [6] in 1997, 31.1\% negative repeat biopsies were found. This is no different from the pT2 tumors in our study. Epstein et al. concluded that tumors which are negative on repeat sextant biopsy do not necessarily represent insignificant cancer. Rabbani et al. [7] reported a $77 \%$ detection rate of repeat sextant biopsy in bioptically-proven organ-confined $\mathrm{CaPs}$ and highlighted the considerable sampling error in significant CaPs. Considering corresponding histologically-confined tumor-positive areas in radical prostatectomy specimens, in a recent study [3] even less than $50 \%$ of the lesions were identified by sextant biopsy. All comparable studies [3, 7, 8], including the present one, demonstrate a remarkably poor redetection rate of repeat sextant biopsy, especially in potentially curable organ-confined cancers. These data have implications for the evaluation of a negative sextant biopsy in men suspected of having CaP. All these patients should be considered candidates for a second sextant biopsy after an interval of some weeks. As demonstrated by Häggman et al. [8] the detection rate could be improved by taking more biopsies. Using 10 core biopsies, they found in 60 patients a detection rate of $92 \%$ after radical prostatectomy.

Besides these considerations involving the detection of significant and potentially curable $\mathrm{CaP}$, the above-mentioned biopsy data raise questions about the clinical value of repeat biopsies in the monitoring of alternatively treated $\mathrm{CaP}$ patients undergoing a prostate-sparing procedure like radiotherapy, high intensive focused ultrasound
(HIFU) or cryoablation. Repeat sextant biopsies have been used as response criteria in the evaluation of the efficacy of cryoablation of prostate [9] and HIFU [10-12]. Albert et al. [10, 11] defined complete response after HIFU for organ-confined $\mathrm{CaP}$ as negative repeated sextant biopsies and reported complete response rates of each $61 \%[10,11]$. In the light of the rate of negative biopsies obtained in pT2 tumors in the present series, one can estimate that the real rate of complete destruction of cancer by HIFU is probably less than $50 \%$, especially considering the difficulty in identifying small residual cancer nests after extensive destruction of the prostate gland. The response criteria established by Thüroff and Chaussy [12] appear even more problematic. These authors used repeat prostate biopsy not only to define complete remission after HIFU but even partial remission, stable and progressive disease, using the number of positive posttreatment biopsies, compared with the pretreatment biopsy. These criteria seem questionable and hardly represent the real status of cancer after HIFU. Repeat biopsies after prostate-sparing treatment for $\mathrm{CaP}$ are probably only suitable for the documentation of treatment failure. Durable complete remission after these treatment modalities should be defined using PSA nadir and PSA velocity rather than repeat sextant biopsies.

\section{Conclusions}

The present study provides further evidence for the relatively low detection rate of organ-confined prostate cancer by conventional sextant biopsy and underlines the need for alternative strategies in the identification of patients who are suitable for curative treatment of $\mathrm{CaP}$. On the other hand, the low detection rate of carcinoma of the prostate in locally confined carcinoma challenges the response criteria based on a repeat sextant biopsy in the evaluation of the efficacy of alternative prostate-sparing treatment modalities for CaP. $\overline{82} \quad \overline{\text { Urol Int 2000;65:80-83 }}$
Manseck/Froehner/Oehlschlaeger/ Hakenberg/Friedrich/Theissig/Wirth 


\section{References}

1 Smart CR: The results of prostate carcinoma screening in the US as reflected in the surveillance, epidemiology, and end results program. Cancer 1997;80:1835-1844.

2 Hodge KH, McNeal JE, Terris MK, Stamey TA: Random systematic versus directed ultrasound-guided transrectal core biopsies of the prostate. J Urol 1989;142:71-75.

3 Salomon L, Colombel M, Patard JJ, LefrereBelda MA, Bellot J, Chopin D, Abbou CC: Value of ultrasound-guided systematic sextant biopsies in prostate tumor mapping. Eur Urol 1999;35:289-293.

4 Stroumbakis N, Cookson MS, Reuter VE, Fair WR: Clinical significance of repeat sextant biopsies in prostate cancer patients. Urology 1997;49(suppl 3A):113-118.
5 Stamey TA, McNeal JE, Freiha FS, Redwine E: Morphometric and clinical studies on 68 consecutive radical prostatectomies. J Urol 1988 ; 139:1235-1241

6 Epstein JI, Walsh PC, Sauvageot J, Carter B: Use of repeat sextant and transition zone biopsies for assessing extent of prostate cancer. J Urol 1997;158:1886-1890.

7 Rabbani F, Stroumbakis N, Kava BR, Cookson MS, Fair WR: Incidence and clinical significance of false-negative sextant prostate biopsies. J Urol 1998;159:1247-1250.

8 Häggman M, Nybacka O, Nordin B, Busch C: Standardized in vitro mapping with multiple core biopsies of total prostatectomy specimens: Localisation and prediction of tumor volume and grade. Br J Urol 1994;74:617-625.
9 Derakshani P, Zumbe J, Heidenreich A, Neubauer S, Engelmann U: Ultrasound-guided cryoablation of organ-confined prostate cancer - Clinical experiences. Eur Urol 1998;34 (suppl 1):A210.

10 Albert G, Chapelon JY, Desgranchamps F, Alain L, Guillonneau B, Vallancien G: Local control of prostate cancer with HIFU: Preliminary results of a French multicentric study. Eur Urol 1998;34(suppl 1):A211.

11 Albert G, Chapelon JY, Bouvier R, Pangaud C, Cathignol D, Dubernard JM: Treatment of prostate cancer with transrectal focussed ultrasound: First clinical experiences. Eur Urol 1998;34(suppl 1):A212.

12 Thüroff S, Chaussy C: High intensive focussed ultrasound against localized prostate cancer. An additional tool before hormonal ablation? Eur Urol 1998;34(suppl 1):A213. 